\title{
Cyclic triaxial test for an unsaturated soil with measurement of hydraulic conductivity
}

\author{
Tomoyoshi. Nishimura ${ }^{\text {i) }}$ and Keita. Iwasaki ${ }^{\text {ii) }}$
}

\begin{abstract}
i) Professor, Department of Civil Engineering, Ashikaga Institute of Technology, 268, Omae, Ashikaga, Tochigi, 326-8558, Japan. ii) Undergraduate student, Department of Civil Engineering, Ashikaga Institute of Technology, 268, Omae, Ashikaga, Tochigi, 3268558, Japan.
\end{abstract}

\begin{abstract}
Implement or performance to unsaturated soil mechanism including concept of cyclic phenomena is necessary to prevent, decrease earthquake-induced great damages. Also, human soil structures such as road-embankment, railway-embankment and river dike have received strong rain fall, and the permeation induce increment of soil moisture and some deformation or settlement regard to safety factor. The experimental works and establish mathematical modelling for unsaturated soil is significant to realize the practice problems. This study aims to interpret unsaturated soil properties subjected saturation-unsaturation. The difference three experimental tests as hydraulic conductivity test, monotonic compression triaxial test and cyclic triaxial test were performed for a silt material, and low matric suction was controlled. The accurate measurement of volume shrinkage was accomplished, that change of void ratio was important factor to interpret the properties of apparent saturation silt. The repetition of saturation-unsaturation induced considerable influence to hydration conductivity and shear strength.
\end{abstract}

Keywords: cyclic triaxial test, unsaturated soils, suction, hydraulic conductivity

\section{INTRODUCTION}

Implement or performance to unsaturated soil mechanism including concept of cyclic phenomena is necessary to prevent, decrease earthquake-induced great damages ${ }^{1223)}$. Also, human soil structures such as road-embankment, railway-embankment and river dike have received strong rain fall, and the permeation induce increment of soil moisture and some deformation or settlement regard to safety factor. The experimental works ${ }^{4}$ and establish mathematical modelling for unsaturated soil is significant to realize the practice problems. This study aims to interpret unsaturated soil properties subjected to repetition of saturationunsaturation. Process of saturation-unsaturation was created as seepage and application of suction, and maximum suction was $20 \mathrm{kPa}$. The difference three experimental tests as hydraulic conductivity test, monotonic compression triaxial test and cyclic triaxial test were performed for a silt material, and low matric suction was controlled. The accurate measurement of volume shrinkage was accomplished, that change of void ratio was important factor to interpret the properties of apparent saturation silt. The repetition of saturationunsaturation induced considerable influence to hydration conductivity and shear strength.

\section{SOIL MATERIAL AND APPARATUS}

This experimental test program used a silt which had a relatively uniform distribution. The silt was called as DL-clay which had a fine content of $99.0 \%$. The soil specimens were statically compacted in the steel mold at the as compacted water content of $10 \%$. The optimum water content was $17 \%$ obtained from compaction test using a rammer (JIS A 1210: 2009). The compacted soil specimen had a dry density of $1.39 \mathrm{~g} / \mathrm{cm}^{3}$, a degree of saturation of $29.2 \%$ and void ratio of 0.910 . The size of specimen was a diameter of $50 \mathrm{~mm}$ and a height of $100 \mathrm{~mm}$.

The soil-water characteristic curve was shown in Fig. 1 which was measured using pressure membrane technique with a range from $0 \mathrm{kPa}$ to $20 \mathrm{kPa}$ in suction. Suction used in this study was defined as between poreair pressure and pore-water pressure. There are obviously hysteresis between drying process and wetting process when the matric suction was less than $6.5 \mathrm{kPa}$. Even the matric suction approached to zero value on wetting process, the degree of saturation not coincident with initial degree of saturation on drying process.

This study used a modified cyclic triaxial apparatus for monotonic triaxial test and cyclic triaxial test. The apparatus consist of vibrator, control equipment, triaxial cell, supply system for cell pressure, pore-water pressure, pore-air pressure and a double glass burette. The axis 


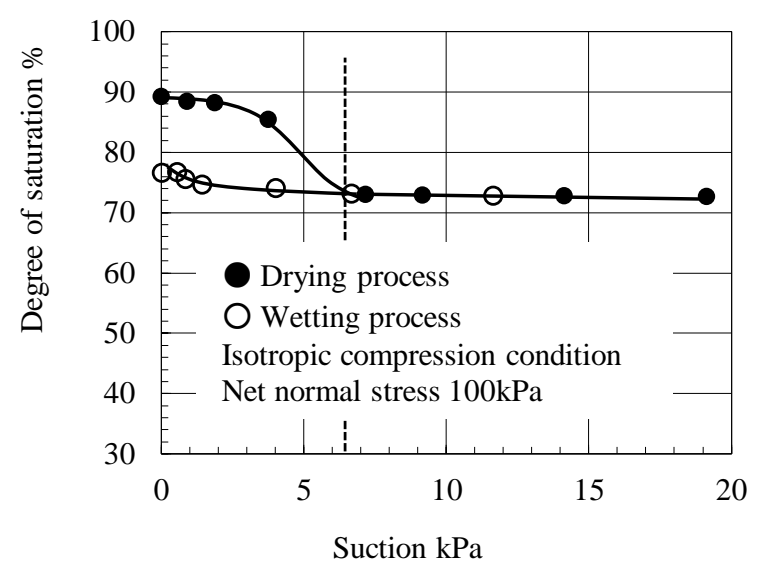

Fig. 1. Soil-water characteristic curve under isotropic compression.

Table 1. Subject for each testing process.

\begin{tabular}{|c|l|}
\hline No & \multicolumn{1}{|c|}{ Process } \\
\hline (1) & Initial soil sample \\
\hline (2) & Apply net normal stress \\
\hline (3) & Apply back pressure \\
\hline (4) & Apply suction by pressure membrane technique \\
\hline (5) & Monotonic triaxial compression test \\
\hline (6) & Seepage \\
\hline (7) & Cyclic triaxial test \\
\hline
\end{tabular}

(5)

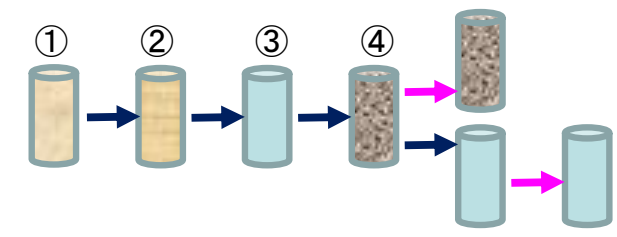

(6) (7)

Fig. 2. Flow of this testing program.

translation technique was used applying matric suction to soil specimen under constant net normal stress. The micro porous membrane which had an air entry value of $250 \mathrm{kPa}$ was installed into the modified pedestal.

\section{TEST PROGRAM}

This test program consists of hydraulic conductivity test, monotonic triaxial compression test and cyclic triaxial test under undrained condition. Fig. 2 shows the summary of triaxial testing program flow and seven different process. After isotropic consolidation, seepage was applied to specimens for deleting initial suction. De-air water was percolated through specimen from bottom, and volume shrinkage was measured due to collapsing phenomena. All specimens approached to apparent saturation condition (i.e. a degree of saturation was less than $100 \%$ ). Subsequently, suction of $20 \mathrm{kPa}$ was applied remaining the net normal stress of $100 \mathrm{kPa}$. After the equilibrium with the confirmed

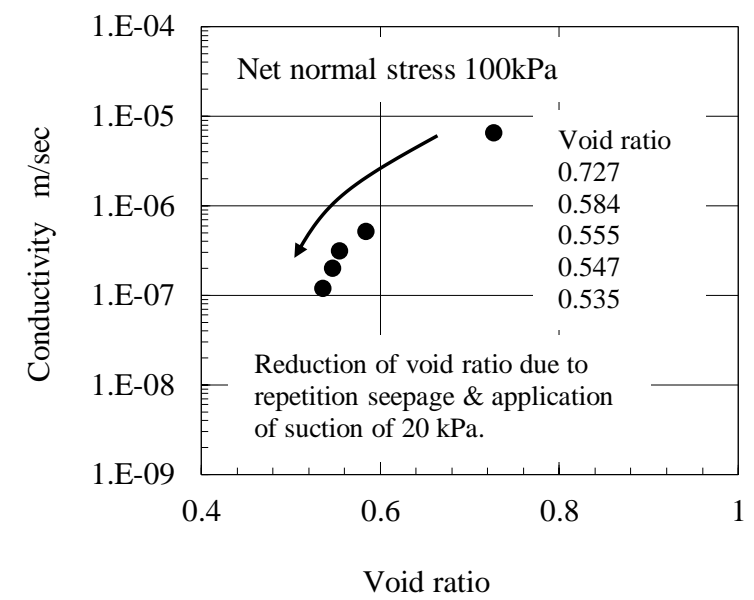

Fig. 3. Reduction of hydraulic conductivity.

suction, monotonic triaxial compression test was performed. Other hands, some specimens were applied seepage, which was similar with above mentioned process. The hydraulic conductivity was measured under net normal stress of $100 \mathrm{kPa}$. The cyclic triaxial test was conducted with controlling of principal stress deviations. All testing conditions were as following; two initial cyclic stress ratios were 0.24 and 0.31 , the applied loading frequency was $0.5 \mathrm{~Hz}$ and undrained condition. The difference between initial cyclic stress ratio corresponded to $14 \mathrm{kPa}$ in deviator stress.

\section{TEST RESULTS}

\subsection{Hydraulic conductivity}

After net normal stress of $100 \mathrm{kPa}$ applied to the specimens. Both seepage and applying of suction were repeated under maintaining of net normal stress, which saturation - unsaturation repetition induced volume shrinkage as shown in Fig. 3. The shrinkage included two components such as collapsing and suction effort. The collapsing is due to decreasing of effective stress or increasing of soil moisture. To apply the suction is related to be dense soil particle together by soil water meniscus effort. Both seepage and applying of suction gradually decreased void ratio. The mount of decrement of void ratio approached to few, and suggested to be equilibrium with 0.536 after five times repetition.

The hydraulic conductivity related to void ratio, which decreased with decrement of void ratio as shown in Fig. 3. The saturation - unsaturation repetition induced that the hydraulic conductivity decreased to about $2.0 \%$ to initial conductivity. The hydration performance such as seepage and suction controlling strictly concerned to unsaturated soil properties.

\subsection{Stress-strain curve on monotonic compression}

Figure 4 show the two difference stress-strain curves obtained from monotonic triaxial compression test. One is suction of $20 \mathrm{kPa}$, other specimen were 


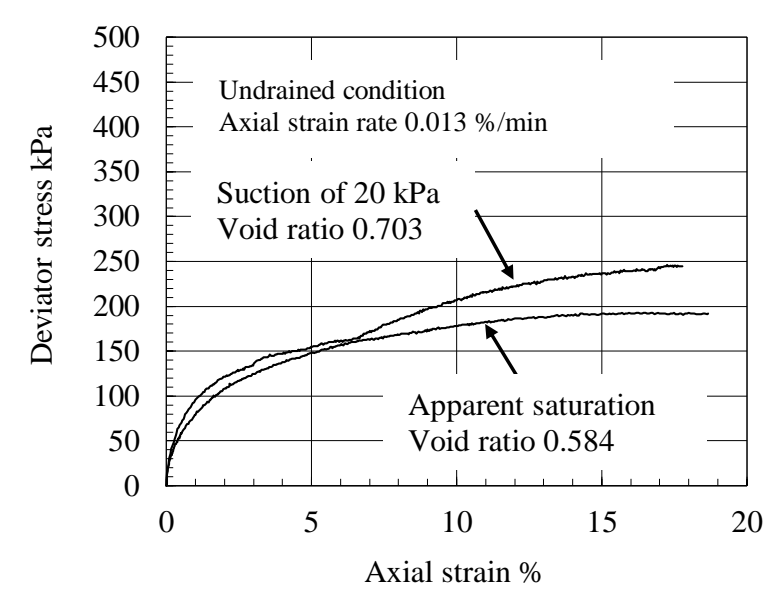

Fig. 4. Effort of suction to shear strength.

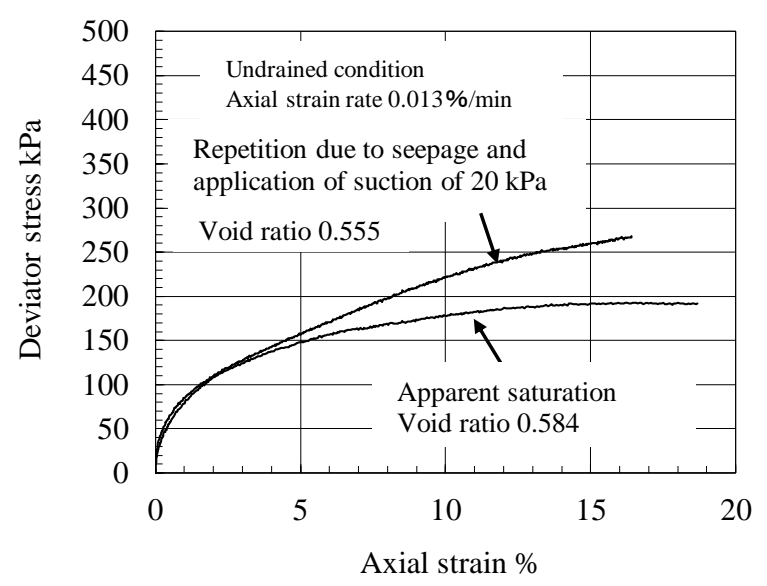

Fig. 5. Increment of shear resistance by repetition.

apparent saturation condition (i.e. suction of zero). An apparent saturated condition meant that the specimen received seepage.

In case of the specimen with suction of $20 \mathrm{kPa}$, the deviator stress increased largely at beginning of compression. Till axial strain was $2.0 \%$, large increment of deviator stress was maintained. At axial strain was over $2.0 \%$, stress and strain curve described smoothly curvature, and the deviator stress approached to maximum value. The residual shear stress was remained.

In case of apparent saturation condition, the occurrence of deviator stress was similar with suction of $20 \mathrm{kPa}$ in the range of small axial strain. The increment of deviator stress was small when the axial strain was over $7.0 \%$. The stress-strain curve located under that of suction of $20 \mathrm{kPa}$. The maximum deviator stress described reduction comparison to suction of $20 \mathrm{kPa}$ at end of test. It was exhibited that suction effort certainly remained shear resistance soil particle together. Also, the residual stress was further decrement due to deprivation of suction.

As above mentioned in Fig. 3, the series of seepage and application of suction caused shrinkage of volume

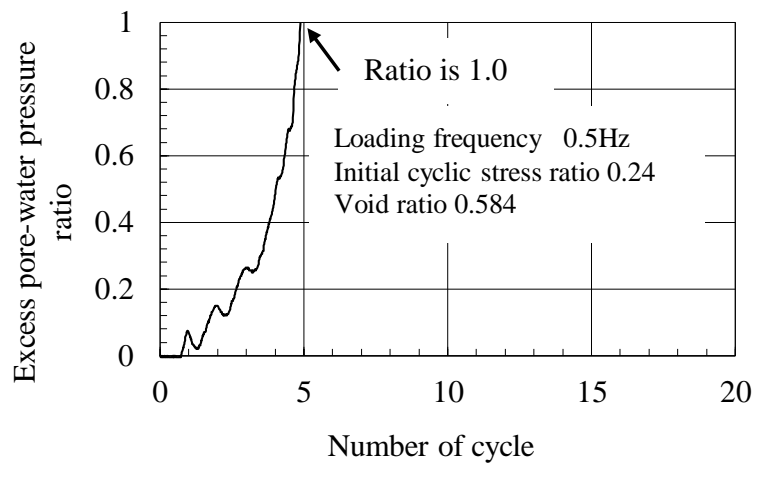

Fig. 6. Excess pore water pressure ratio.

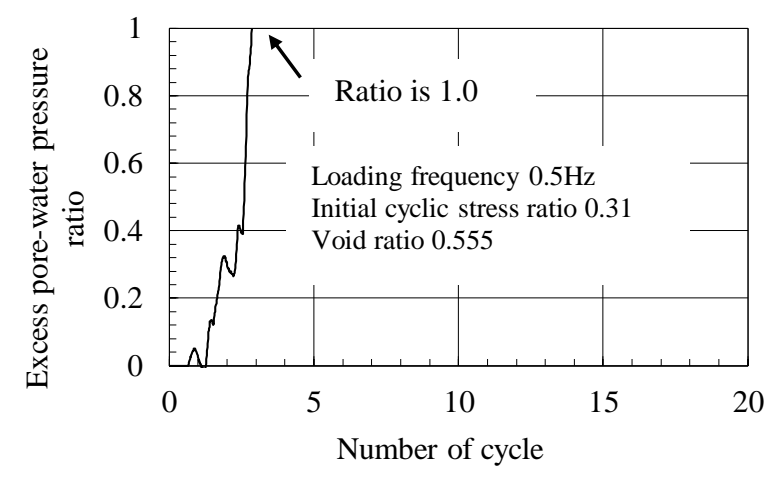

Fig. 7. Excess pore-water pressure ratio.

(i.e. decrement of void ratio) for an unsaturated silt soil. The monotonic triaxial compression test conducted out subjected to alternating seepage and application of suction.

The specimen subjected to three repetition indicated the decreasing of void ratio that was from 0.910 to 0.555 . The obtained stress-strain curve was described in Fig. 5. Influence of repetition on shear properties was clearly indicated that stress-strain curve was placed upper that of specimen subjected to once time (i.e. apparent saturation mentioned in Fig. 4). The deviator stress behavior till axial strain was $4.0 \%$ which was similar with that of apparent saturation condition. The increment was larger than apparent saturation condition beyond the axial strain of $5.0 \%$. It caused that there was difference in void ratio before shearing. Finally, the shear strength was further high comparison to apparent saturation condition.

\subsection{Cyclic behavior under undrained condition}

Two apparent saturated specimens were performed on cyclic triaxial test undrained condition that each specimen had the difference void ratio at beginning cyclic test. Their values were 0.584 and 0.555 in void ratio, which number of repetition for seepage and applying of suction caused the difference. Also, initial cyclic stress ratios were 0.24 and 0.31 , respectively. 


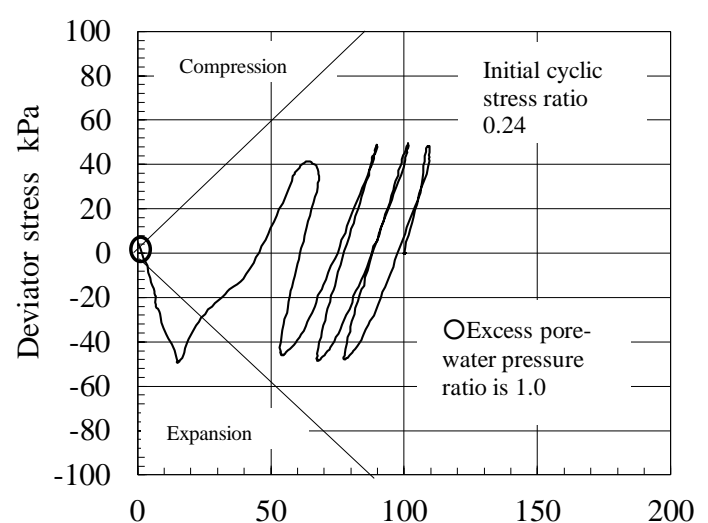

Mean effective principal stress $\mathrm{kPa}$

Fig. 8. Effective stress paths (void ratio 0.584).

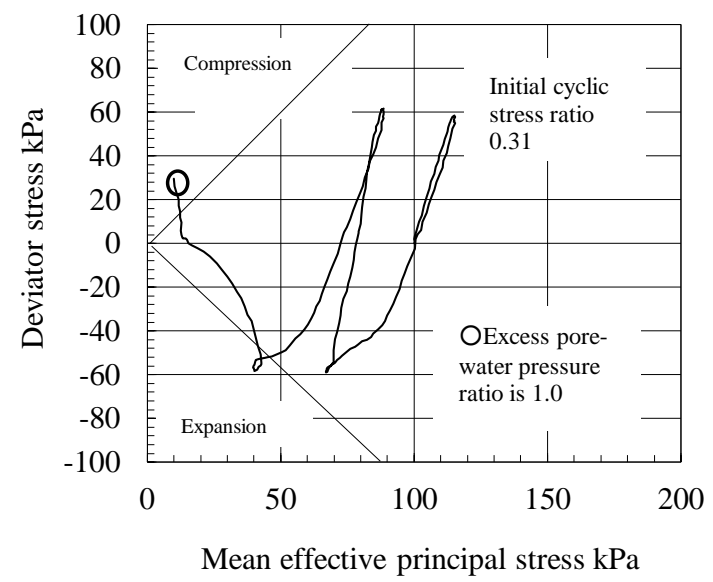

Fig. 9. Effective stress paths (void ratio 0.555).

The dense specimen (i.e. void ratio of 0.555 ) had been applied higher cyclic tress ratio.

Figures 6 and 7 showed the changing of excess porewater pressure ratio with number of cycles which measured at bottom of specimens throughout the microporous membrane. As two specimens were not fully saturation, the occurrence of excess pore-water pressure were low till number of cycles was two. Simultaneously, the deformation to cyclic stress was distinguished and superiority in shrinkage. After number of cycles was over two, the excess pore-water pressure indicated immediately 1.0 that observed the quite destruction and destroy for specimens. The lateral strain of lower portion was extremely large. In case of void ratio of 0.555 , the excess pore water pressure achieved to 1.0 first that was low hydraulic conductivity as mentioned in Fig. 3.

Figures 8 and 9 show the relationship between mean effective principal stress and deviator stress. Failure envelop obtained from monotonic triaxial compression test was accomplished, which was required immutable about compression and expansion as conventional assumption. All of specimens described that each effective stress accurately achieved to zero value at few cycle numbers. It was adapted that destroy seemed to be at expansion side because the stress path made close and contact to envelope of expansion. It was difficult to evaluate the influence of seepage and application of suction repetition on cyclic behavior.

\section{CONCLUSIONS}

This study focused on properties such as hydraulic conductivity, monotonic triaxial compression behavior and dynamic behavior using a modified cyclic triaxial apparatus. The suction control was performed on pressure membrane technique, which used a microporous membrane. The summary obtained from three testing programs are indicated as following;

The hydraulic conductivity clearly decreased after saturation-unsaturation repetition, which reduction of void ratio due to collapsing or volume shrinkage caused.

The shear strength to effort of suction was quiet distinct, and shear resistance of apparent saturated condition certainly described a reduction.

Saturation-unsaturation repetition induced the decreasing of void ratio and the increasing of shear strength for apparent saturation sample.

Apparent saturation sample with decreasing of void ratio indicated the drop of effective stress under cyclic application, and lateral expansion was distinct. Also, first failure occurred at expansion side of failure envelope.

\section{REFERENCES}

1) Koseki, J., Nakajima, S., Tateyama, M., Watanabe, K. and Shinoda, M. (2009): Seismic performance of geosyntheticreinforced soil retaining walls and their performance-based design in Japan, Proceedings of the International Conference on performance-based design in earthquake geotechnical Engineering, IS-Tokyo 2009, pp.149-162.

2) Nishimura, T. (2013): Liquefaction test of compacted, unsaturated soil and saturated soil with controlling matric suction, The 5th International Geotechnical Symposium, IGSIncheon 2013, pp.279-284.

3) Tanaka, T. (2013): Dynamic response analysis for unsaturated embankment dam by elasto-plastic constitutive relation, The 5th International Geotechnical Symposium, IGS-Incheon 2013, pp.24-29.

4) Tokida, K. (2009): Natural dams built by sliding failure of slope during the Iwate-Miyagi Nairiku Earthquake in 2008, Proceedings of the International Symposium on Prediction and Simulation Methods for Geohazard Mitigation, IS-Kyoto 2009, 25-27 May 2009. pp. 583-590. 